\title{
Morphological, Electrical and Thermal Performances for Rubber High Voltage Applications
}

\author{
Shaymaa A. Qenawy ${ }^{1 *}$, Loai S. Nasrat ${ }^{2}$, Hanafy M. Ismail ${ }^{1}$, Jeannette N. Asaad ${ }^{3}$ \\ ${ }^{1}$ Electrical Power and Machines Engineering Department, Ain Shams University, Cairo, Egypt \\ ${ }^{2}$ Electrical Engineering Department, Aswan University, Aswan, Egypt \\ ${ }^{3}$ Polymers and Pigments Department, National Research Centre, Cairo, Egypt \\ *Corresponding Author \\ Shaymaa A. Qenawy
}

\section{Article History}

Received: 23.06.2020

Accepted: 01.07.2020

Published: 09.07.2020

\begin{abstract}
Addition of fillers to silicone rubber (SR) insulating materials has gained wide interest. Therefore, preparation of micro and nano composite materials will be helpful both for the users and manufacturers for improving electrical and thermal performances of insulators for high voltage applications. This paper deals with the experimental studies on the morphological, electrical and thermal characteristics of low weight \% Zeolite (Z) filled nanocomposites and highly filled microcomposites. For the performance comparison breakdown strength and thermogravimetric analysis (TGA) test have been done on the SR specimens. Scanning electron microscopy (SEM) studies were conducted to understand the dispersion of the filler and the changes in surface morphology in both microcomposite and nanocomposite specimens. The results indicate that the electrical and thermal performances of microcomposites and nanocomposites are increased with the increase of filler concentration. Maximum breakdown strength value and TGA value were obtained from nanocomposite with $7 \mathrm{wt} \%$ filler concentration.
\end{abstract}

Keywords: Silicone Rubber, Micro and Nano Fillers, Breakdown Strength, Scanning Electron Microscopy, Thermogravimetric Analysis.

\section{INTRODUCTION}

Outdoor composite polymeric insulators have many advantages such as good vandalism resistance, easy transportation and installation and light weight, also provide better performance under contaminated environments. Outdoor polymeric insulators are considered as one of the backbone components in the power system network.

SR is made of organic material. Therefore, the deterioration caused by environmental stresses such as UV, heat, condensation and acidic compound will affect the electrical and thermal performance of the material over time. Aging of the composite insulators can be evaluated by material characterization techniques such as hydrophobicity, dielectric strength, color, surface roughness, breakdown strength test and chemical composition [1].

For improving electrical, mechanical, thermal and physical properties of the polymer, a few weight percent of nano fillers have been loaded [2-3]. Significant changes of electrical and mechanical properties could be achieved with nano filler concentrations of less than $10 \mathrm{wt} \%$ [4-6]. The interactions between nano particles and polymer are considered to be the reason for these effects.

In recent years, there has been a global interest in application of nano dielectrics in the area of electrical insulation and numerous outcomes proclaimed that polymeric nano composites can be advantageous for outdoor insulation applications.

Dielectric materials with high breakdown strength are beneficial for HV and large capacity as well as miniaturized power equipment and electronic devices [7-9].

The dielectric breakdown of polymers in HV devices is a major factor establishing a relationship between

Copyright @ 2020: This is an open-access article distributed under the terms of the Creative Commons Attribution license which permits unrestricted use, distribution, and reproduction in any medium for non commercial use (NonCommercial, or CC-BY-NC) provided the original author and source are credited. 
inherent material properties and its dielectric performance [10-13]. The dielectric breakdown generally occurs within an insulating material in a narrow conducting channel between electrodes and is known to be irreversible and destructive.

Environmental conditions such as pollution, salinity and moisture can have large influences on the electrical performance of insulators. Salt deposits near the coast or inland areas such as near major freeways in northern climate during winter are sources of pollutions. When an insulator is dry, there is no problem. However, when it is wet, the surface resistance drops considerably [14-15].

This work focuses on studying, analyzing and documenting the effect of micro and nano Zeolite filler on the morphological, electrical and thermal properties of SR insulators.

\section{EXPERIMENTAL}

\section{Materials}

Silicone rubber was selected as a base matrix and supplied by sonax, Germany. The inorganic fillers were used such as micro and nano Zeolite are an effective flame retardant for polymers and supplied by Nano Tech Egypt.

\section{Preparation of Composites}

The specimens were prepared by mixing micro/nano fillers with SR as the base polymer and the concentrations of fillers were taken as percentage of the total weight of the base polymer. A pure silicone rubber sample was considered as reference. The mixture between SR and micro filler is prepared in the lab using two roll mill mixer. The specimens were left at night before vulcanization. The vulcanization of the specimens was applied under a pressure of $40 \mathrm{~N} / \mathrm{cm}^{2}$ and a temperature of $150^{\circ} \mathrm{C}$ for about $10 \mathrm{~min}$. Fig-1 shows the rolling machine which is used for preparation. The specimens were cut and prepared with dimensions that best suited each testing method according to ASTM. Nine different types of samples were fabricated with the composition shown in Table 1.

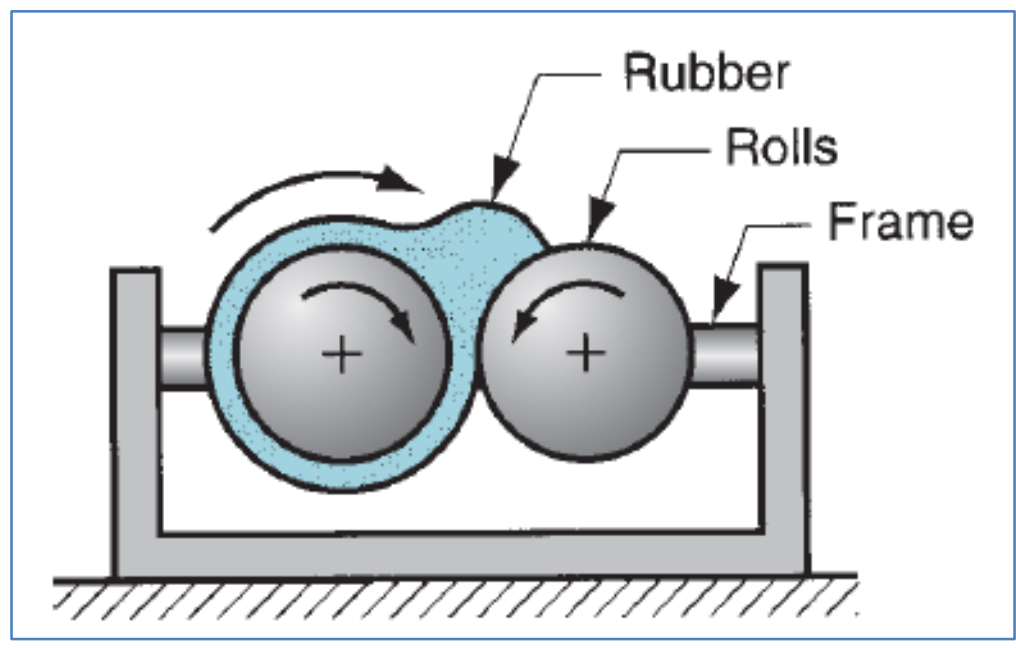

Fig-1: Two roll mill mixer used in SR processing

Table-1: Zeolite particle contents in composites

\begin{tabular}{|c|c|c|}
\hline Type of filler & Percentage of filler (\%) & Acronym \\
\hline Pure Silicone Rubber & 0 & PSR \\
\hline \multirow{3}{*}{ Micro Zeolite } & 10 & MZ10 \\
\cline { 2 - 3 } & 20 & MZ20 \\
\cline { 2 - 3 } & 30 & MZ30 \\
\cline { 2 - 3 } & 40 & MZ40 \\
\hline \multirow{3}{*}{ Nano Zeolite } & 1 & NZ1 \\
\cline { 2 - 3 } & 3 & NZ3 \\
\cline { 2 - 3 } & 5 & NZ7 \\
\cline { 2 - 3 }
\end{tabular}

\section{Characterization}




\section{Microstructure Observation}

Scanning electron microscope (SEM) was performed using a JSM-840A electron probe micro- analyzer (JOEL, Japan), this analysis was used in this study to determine the dispersion of the pigment particles in the SR matrix. The samples were cut into $1 \mathrm{~cm}$ in length. The test was done by breaking the SR sample in liquid nitrogen; then covering the cross section surface with a very thin layer of gold to avoid electrostatic charging during examination.

\section{Breakdown Strength Test}

The breakdown strength of an insulating material is defined as the maximum voltage that it can withstand intrinsically without breaking down, i.e., without experiencing failure of its insulating properties accompanied with an arc current. Set of mixing specimens have been prepared and tested The SR composite specimens have been tested using AC $(50 \mathrm{~Hz})$ with $25 \mathrm{~mm}$ diameter mushroom electrodes to study the breakdown strength under different contaminated conditions. The faces of electrodes were parallel and free from pits or other imperfections as shown in Fig-2. The voltage was gradually increased at an almost constant rate of $4 \mathrm{kV} / \mathrm{sec}$ until the voltage breakdown occurs. Measurements were made on nine SR composites specimens. In this paper, the breakdown strength of the micro and nano composites is measured using the circuit shown in Fig-3. The average results for nine specimens of each test has been taken to minimize the error. Breakdown strength properties were studied at three conditions such as dry, wet and salinity condition as shown in Table 2.

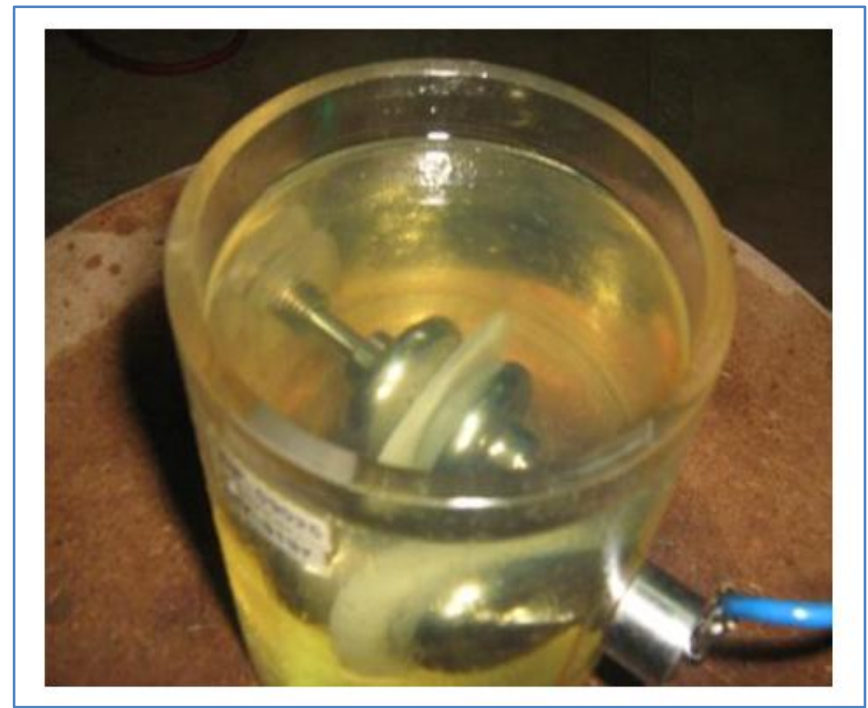

Fig-2: Mushroom shaped electrodes used during AC breakdown strength measurements

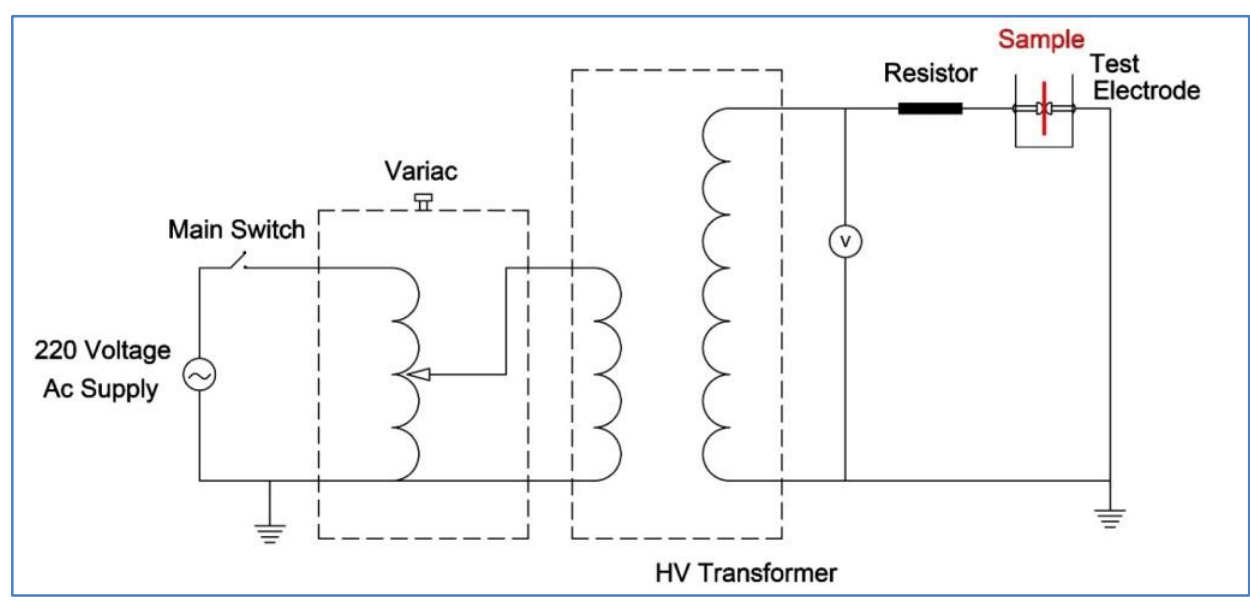

Fig-3: Schematic diagram used for breakdown strength test 


\begin{tabular}{|c|c|}
\hline Test Condition & Description of Each Test \\
\hline Dry Condition & $\begin{array}{l}\text { The specimens should be clean and dry before starting the test to remove dust and other } \\
\text { contaminated particles. } \\
\text { The time intervals between the voltages applied on each sample should be suitable and sufficient. } \\
\text { Specimens can be tested while surrounded with oil. Oil helps to prevent the voltage from arcing } \\
\text { through the air around the sides of the panel and instead forces it to burn through the specimen. This } \\
\text { test assessed by ASTM D149 [16] at room temperature }\left(25^{\circ} \mathrm{C}\right) \text { and at a relative humidity of } 21 \% \text {. }\end{array}$ \\
\hline Wet Condition & $\begin{array}{l}\text { This test carried out to show the effect to show the effect of water on breakdown strength of } \\
\text { Zeolite/SR composites. } \\
\text { The specimens should be paced in a container of distilled water maintained at a temperature of } \\
23 \pm 1^{\circ} \mathrm{C} \text {, and be entirely immersed. } \\
\text { At the end of } 24 \text { hrs, the specimens should be removed from the water one at a time, all surface } \\
\text { water wiped off with a dry cloth. } \\
\text { The specimens should be immersed in oil to prevent occurring of flashover, this test determined } \\
\text { according to ASTM D570 [17]. }\end{array}$ \\
\hline $\begin{array}{c}\text { Salinity } \\
\text { Condition }\end{array}$ & $\begin{array}{l}\text { This test carried out to simulate of coastal areas near seas. The salient solution has been prepared } \\
\text { using sodium chloride }(\mathrm{NaCl}) \text { and distilled water. } \\
\text { The specimens should be paced in a container of salient solution maintained at a temperature of } \\
23 \pm 1^{\circ} \mathrm{C} \text {, and be entirely immersed. } \\
\text { At the end of } 24 \mathrm{hrs} \text {, the specimens should be removed from the salient solution one at a time, all } \\
\text { surface water wiped off with a dry cloth. } \\
\text { The specimens should be immersed in oil to prevent occurring of flashover, this test determined } \\
\text { according to ASTM D570. }\end{array}$ \\
\hline
\end{tabular}

\section{Thermal Test}

Thermo gravimetric analysis (TGA) is performed to discuss the thermal stability of materials, estimated life of composite specimens and fire retardant properties according to ASTM E1131 [18]. TGA estimates the amount and rate of change in the mass of the specimen as a function of temperature in a controlled atmosphere.

\section{ReSUlTS AND DiscUSSION}

\section{Physical Property Analysis Using SEM}

The surface physical change was examined by SEM. Fig-4 shows the SEM images, indicating an improvement in the dispersion of the Zeolite filler particles in the SiR matrix owing to the surface modification.

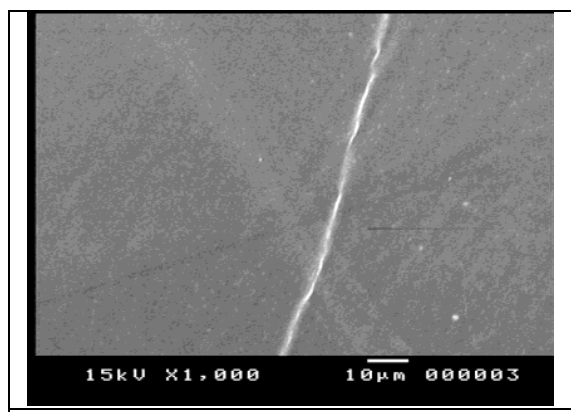

(a)

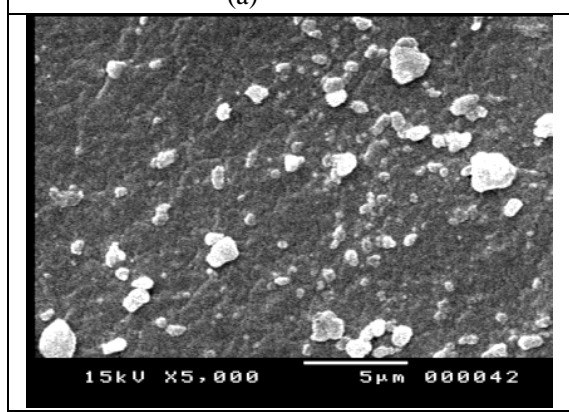

(d)

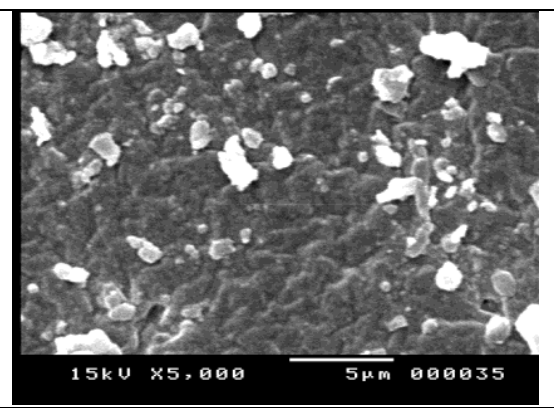

(b)

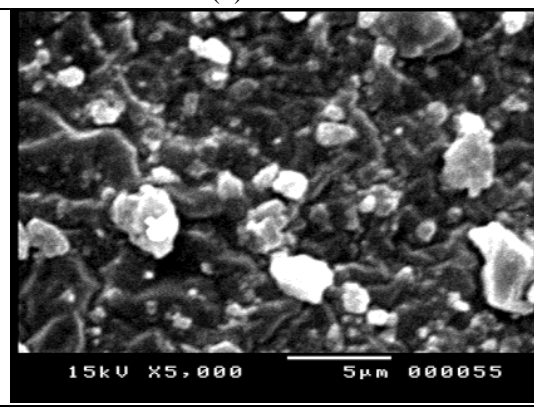

(e)

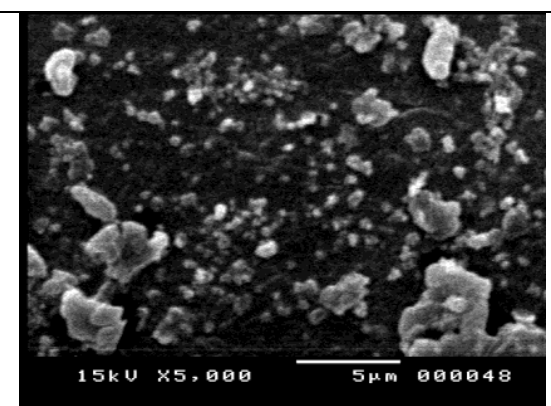

(c)

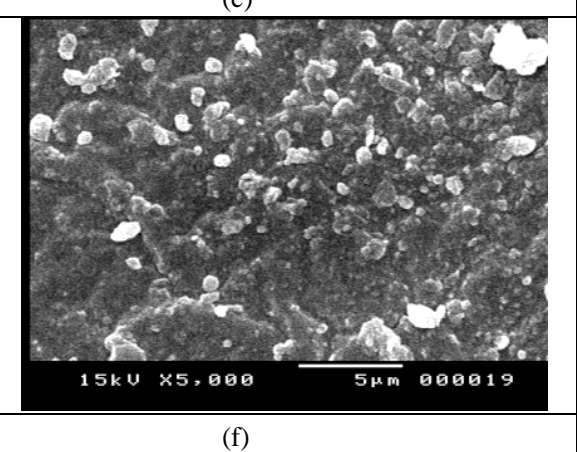




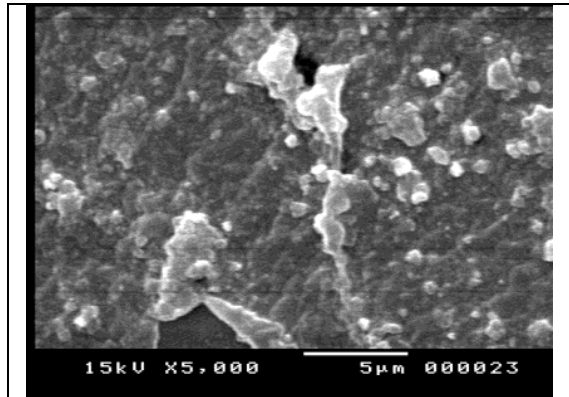

(g)

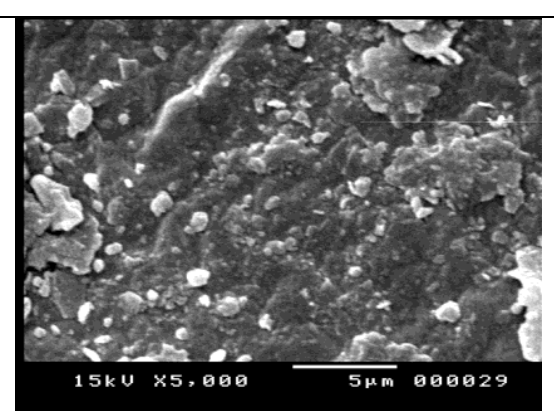

(h)

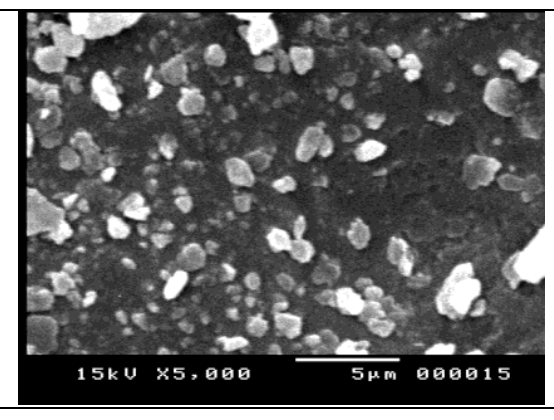

(i)

Fig-4: SEM micrographs of the Z/SR composite samples (a) PSR, (b) MZ10, (c) MZ20, (d) MZ30, (e) MZ40, (f) NZ1, (g) NZ3, (h) NZ5, and (i) NZ7

The filler particles are enswathed in the SR matrix and filler increases. But along with the increase in the content of $\mathrm{Z}$, the $\mathrm{Z}$ particles aggregate seriously as shown in Fig-4.

It can be seen from Fig-4 that agglomeration of particles can be clearly observed in the SEM photos which increase as $\mathrm{Z}$ filler content increases results into weak interaction between agglomerated filler particles and SR matrix. It can also be observed from Fig-4 that the surface of the pure SR specimen is smooth and just distributed filler is apparent on it.

It is notable from Fig-4 that because of the very nature of the nano particles, ideal distribution is very difficult. Some agglomerations have been formed in the nanocomposite. Consequently, the distribution of the filler in the nanocomposite can be considered reasonably good.

The good bonding between the nano filler and the SR matrix improves the electrical and thermal properties of the nano- composites. This is due to the reduced size of the filler which in turn leads to a better bonding between the filler and the SR matrix.

The nano particles were uniformly distributed without the introduction of voids and other defects. It also can be seen from Fig-4 that specimen NZ7 has the strongest interaction between filler and SR matrix.

\section{Breakdown Strength Test Results}

The breakdown strength experimental measurements have been recorded in laboratory for SR polymer insulator with micro and nano $\mathrm{Z}$ at different conditions. Tables 3, 4, 5 and 6 represent the values of breakdown strength $(\mathrm{kV} / \mathrm{mm})$ for the micro and nano Zcomposite specimens under different conditions.

Table-3: Breakdown strength of micro and nano $\mathrm{Z}$ composite specimens under dry condition

\begin{tabular}{|c|c|c|}
\hline Acronym & Test condition & Breakdown strength $(\mathrm{kV} / \mathrm{mm})$ \\
\hline PSR & \multirow{9}{*}{ Dry Condition } & 31.22 \\
\hline NZ1 & & 31.98 \\
\hline NZ3 & & 33.13 \\
\hline NZ5 & & 35.71 \\
\hline NZ7 & & 37.25 \\
\hline MZ10 & & 33.25 \\
\hline MZ20 & & 35.44 \\
\hline MZ30 & & 37.04 \\
\hline MZ40 & & 35.98 \\
\hline
\end{tabular}

Table-4: Breakdown strength of micro and nano $Z$ composite specimens under wet condition

\begin{tabular}{|c|c|c|}
\hline Acronym & Test condition & Breakdown strength $(\mathrm{kV} / \mathrm{mm})$ \\
\hline PSR & \multirow{9}{*}{ Wet Condition } & 29.20 \\
\hline NZ1 & & 30.02 \\
\hline NZ3 & & 31.54 \\
\hline NZ5 & & 33.54 \\
\hline NZ7 & & 35.23 \\
\hline MZ10 & & 31.35 \\
\hline MZ20 & & 33.46 \\
\hline MZ30 & & 35.43 \\
\hline MZ40 & & 33.43 \\
\hline
\end{tabular}


Table-5: Breakdown strength of micro and nano $\mathrm{Z}$ composite specimens under low salinity condition

\begin{tabular}{|c|c|c|}
\hline Acronym & Test condition & Breakdown strength $(\mathrm{kV} / \mathrm{mm})$ \\
\hline PSR & \multirow{9}{*}{ Low Salinity Condition } & 28.45 \\
\hline NZ1 & & 29.44 \\
\hline NZ3 & & 29.94 \\
\hline NZ5 & & 32.68 \\
\hline NZ7 & & 34.75 \\
\hline MZ10 & & 30.54 \\
\hline MZ20 & & 32.41 \\
\hline MZ30 & & 34.64 \\
\hline MZ40 & & 32.70 \\
\hline
\end{tabular}

Table-6: Breakdown strength of micro and nano $\mathrm{Z}$ composite specimens under high salinity condition

\begin{tabular}{|c|c|c|}
\hline Acronym & Test condition & Breakdown strength $(\mathrm{kV} / \mathrm{mm})$ \\
\hline PSR & \multirow{9}{*}{ High Salinity Condition } & 26.03 \\
\hline NZ1 & & 27.11 \\
\hline NZ3 & & 27.78 \\
\hline NZ5 & & 30.11 \\
\hline NZ7 & & 32.45 \\
\hline MZ10 & & 28.31 \\
\hline MZ20 & & 30.33 \\
\hline MZ30 & & 32.29 \\
\hline MZ40 & & 30.42 \\
\hline
\end{tabular}

It can be seen from the Tables that compared with both neat and micro filled with SR, for all SR micro composites, there is an enhancing in breakdown strength. The micro $\mathrm{Z}$ composite of $30 \%$ records the maximum breakdown strength when compared with other concentration of the same particle size of filler.

It can be also observed from the Tables that the electrical properties of SR composite filled with $\mathrm{Z}$ is reliable at $7 \%$ nano particle size and has breakdown strength better than micro $\mathrm{Z}$.

The breakdown strength of nano $\mathrm{Z}$ composites is higher than breakdown strength of micro $\mathrm{Z}$ composites at any concentrations as shown in the Tables. The SR composite reaches maximum breakdown strength by increasing the filler concentration. If the filler concentration exceeds critical values, the breakdown strength decreases.

The environmental conditions (such as wet, low salinity and high salinity) lead more changing of breakdown strength values, where dry condition has the best value but high salinity has the minimum one for the same type of filler.

\section{Thermogravimetric Analysis}

TGA gives the change in weight loss of a sample with respect to temperature in a controlled atmosphere. As the temperature increases, weight loss occurs due to the release of moisture or gases from the decomposition of the material. TGA provides definitive data for materials and product design and aging stability information with short test times.

\section{Studying TGA for SR Composite Samples Filled with Micro Zeolite Filler}

Fig-5 studies the effect of the thermal stability on SR samples filled with different concentrations of micro $\mathrm{Z}$ filler to determine changes in weight of a sample in relation to change in temperature.

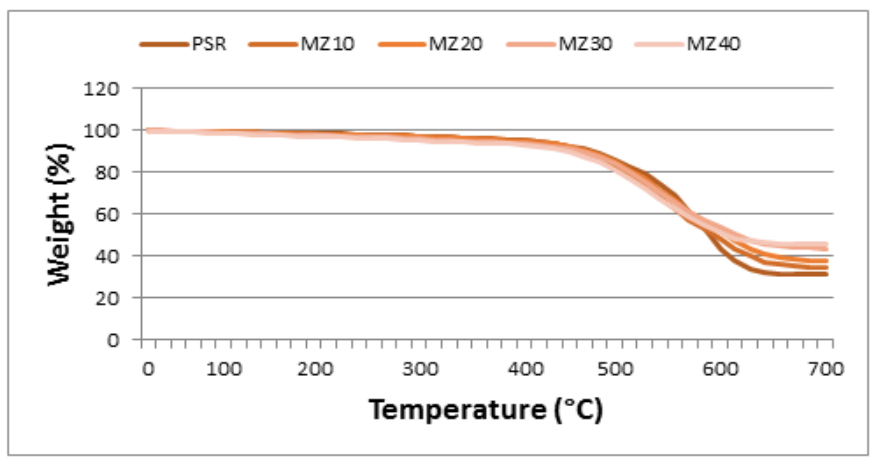

Fig-5: TGA for SR with different micro Zeolite filler concentration 
The measurement was carried out from $35^{\circ} \mathrm{C}$ to $700^{\circ} \mathrm{C}$ in nitrogen atmosphere. It can be seen that weight loss of composite filled with $40 \mathrm{wt} \%$ of Zeolite gave the best thermal stability compared with all composite sample and with unfilled one as shown in Fig-5. It can be concluded from Fig-5 that thermal stability of SR improved by increase of filler percentage.

\section{Studying TGA for SR Composite Samples Filled with Nano Zeolite Filler}

The TGA results for pure SR was used to estimate the weight loss of 1, 3, 5, and 7wt\% filled composite is shown in Fig-6.

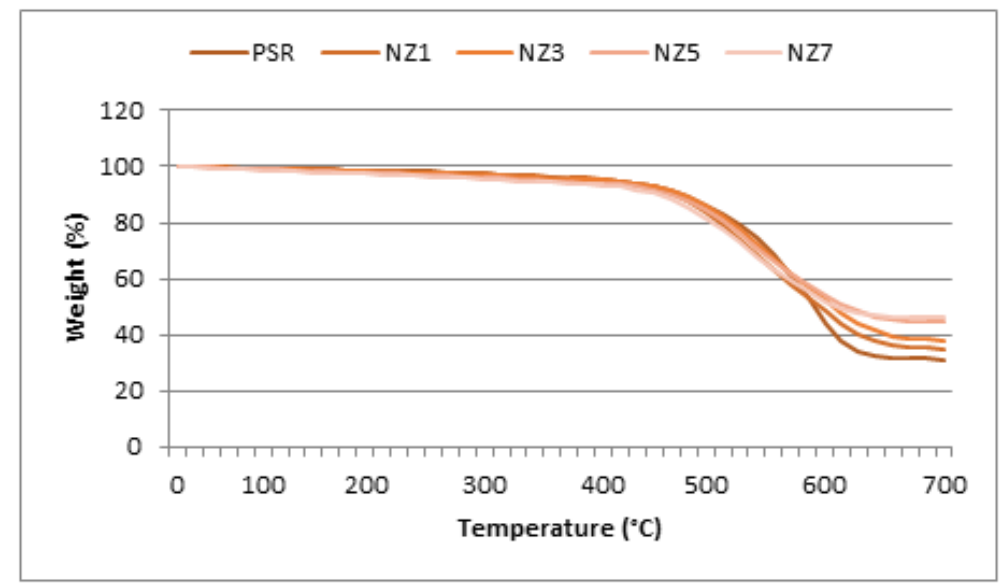

Fig-6: TGA for SR with different nano Zeolite filler concentration

\section{It can be investigated from Fig-6 that}

i. The weight loss increased by temperature rise for all composites.

ii. The weight loss is inversely proportional to the loading concentration of nano Zeolite filler. As the concentration of nano Zeolite in SR increased from $1 \mathrm{wt} \%$ to $7 \mathrm{wt} \%$, the rate of weight loss decreased.

iii. The thermal stability of SR filled with nano Zeolite $(7 \mathrm{wt} \%)$ is better than SR filled with nano Zeolite concentrations $(1,3$ and $5 \mathrm{wt} \%)$.

\section{CONCLUSION}

The studies presented in this paper emphasize different morphological, electrical and thermal behavior of the SR micro and nano composites with Zeolite particles depending on the filler concentration and the structure of the polymer host.

The electrical performance has been improved significantly with nano filler loading. Use of lower contents of filler as in the nanocomposite can lead to better flexibility, ease of processing during the product manufacturing and at the same time improve electrical performance. Thermogravimetric analysis (TGA) of nanocomposite is better than microcomposite. Nano Zeolite composite of $7 \mathrm{wt} \%$ gave maximum breakdown strength and TGA.

\section{ACKNOWLEDGMENT}

The authors acknowledge the facilities and the scientific and technical assistance of the Electrical Engineering Department in Ain Shams and Aswan Universities, National Research Centre (Polymers and Pigments Department), and National Institute of Standards (NIS).

\section{REFERENCES}

1. Haddad, G., Wong, K. L., \& Petersen, P. (2016). Evaluation of the aging process of composite insulator based on surface charaterisation techniques and electrical method. IEEE Transactions on Dielectrics and Electrical Insulation, 23(1), 311-318.

2. Tanaka, T., Montanari, G. C., \& Mulhaupt, R. (2004). Polymer nanocomposites as dielectrics and electrical insulation-perspectives for processing technologies, material characterization and future applications. IEEE transactions on Dielectrics and Electrical Insulation, 11(5), 763-784.

3. Frechette, M. F., Trudeau, M. L., Alamdar, H. D., \& Boily, S. (2004). Introductory remarks on nanodielectrics. IEEE Transactions on Dielectrics and Electrical Insulation, 11(5), 808-818.

4. Fréchette, M. F., Vijh, A., Trudeau, M. L., Utracki, L., Sami, A., David, É., ... \& Vaughan, A. (2010, July). Nanodielectrics: A "universal" panacea for solving all electrical insulation problems?. In 2010 10th IEEE 
International Conference on Solid Dielectrics (pp. 1-3). IEEE.

5. Cheema, T. A., \& Garnweitner, G. (2012). Herstellung von Nanokompositen mit optimierten Eigenschaften aus chemisch maßgeschneiderten Nanopartikeln. Chemie Ingenieur Technik, 3(84), 301-308.

6. Nelson, J. K. (2010). Dielectric polymer nanocomposites. US: Springer

7. Montanari, G. C. (2011). Bringing an insulation to failure: the role of space charge. IEEE Transactions on Dielectrics and Electrical Insulation, 18(2), 339-364.

8. Laurent, C., Teyssedre, G., Le Roy, S., \& Baudoin, F. (2013). Charge dynamics and its energetic features in polymeric materials. IEEE Transactions on Dielectrics and Electrical Insulation, 20(2), 357-381.

9. Bjellheim, P., \& Helgee, B. (1994). AC breakdown strength of aromatic polymers under partial discharge reducing conditions. IEEE Transactions on Dielectrics and Electrical Insulation, 1(1), 89-96.

10. O’dwyer, J.J. (1982). Breakdown in solid dielectrics. IEEE Transaction on Dielectric and Electrical Insulation, 17(6), 484-487

11. Ieda, M. (1980). Dielectric breakdown process of polymers. IEEE Transaction on Dielectric and Electrical Insulation, 15(3), 206-224

12. Helgee, B., \& Bjellheim, P. (1991). Electric breakdown strength of aromatic polymers: dependence on film thickness and chemical structure. IEEE transactions on electrical insulation, 26(6), 1147-1152.

13. He, L., \& Gorur, R. S. (2016). Source strength impact analysis on polymer insulator flashover under contaminated conditions and a comparison with porcelain. IEEE Transactions on Dielectrics and Electrical Insulation, 23(4), 21892195.

14. Kumagai, S., \& Yoshimura, N. (2001). Tracking and erosion of HTV silicone rubber and suppression mechanism of ATH. IEEE Transactions on dielectrics and electrical insulation, 8(2), 203-211.

15. Venkatesulu, B. Y. T. M. J., \& Thomas, M. J. (2010). Erosion resistance of alumina-filled silicone rubber nanocomposites. IEEE Transactions on Dielectrics and Electrical Insulation, 17(2), 615-624.

16. ASTM D149. (2020). Standard test method for dielectric breakdown voltage and dielectric strength of solid electrical insulating materials at commercial power frequencies. ASTM International, West Conshohocken, PA

17. ASTM D570. (2018). Standard test method for water absorption of plastics. ASTM International, West Conshohocken, PA

18. ASTM E1131. (2020). Standard test method for compositional analysis by thermogravimetry. ASTM International, West Conshohocken, PA. 